\title{
Spatial rice decision support system for effective rice crop management
}

\author{
B. Sailaja ${ }^{1, *}$, S. R. Voleti ${ }^{1}$, D. Subrahmanyam ${ }^{1}$, P. Raghuveer Rao ${ }^{1}$, S. Gayatri ${ }^{1}$, \\ R. Nagarjuna Kumar ${ }^{2}$ and Shaik N. Meera ${ }^{1}$ \\ ${ }^{1}$ Indian Institute of Rice Research, Rajendranagar, Hyderabad 500 030, India \\ ${ }^{2}$ Central Research Institute for Dryland Agriculture, Santoshnagar, Hyderabad 500 059, India
}

\begin{abstract}
Rice, a widely grown crop all over the world provides food security to millions of people. The average productivity of rice in India is still low due to diversified environments under which it is being cultivated. Prediction and assessment of rice yields needs simplified precision models. A spatial rice decision support system (SRDSS) was designed by integrating ClimGen climate model and Oryza2000 crop model with soil and weather layers. This DSS facilitates input model parameters and geo-referenced maps to predict rice yield at polygon/pixel level. SRDSS is useful to researchers and planners not only in estimating rice yield but also to estimate optimum crop sowing dates and management practices to achieve target yield for the selected location. Further, SRDSS will be integrated with weather sensors to generate real time advisories to farmers at each level of decision making and to plan and achieve the targets of doubling the farmer's income by 2022 .
\end{abstract}

Keywords: ARCGIS, ClimGen, Oryza2000, rice yield, SRDSS.

RICE is the most important crop and livelihood for millions in India. It is widely cultivated in diverse ecologies and agro-ecological zones. The crop ranks first in the use of land and water resources utilizing $>15$ soil groups, $>50 \%$ of irrigation water, $35 \%$ of fertilizers and $17-18 \%$ of pesticides ${ }^{1}$. Despite significant investments in rice research (high yielding varieties; coverage 84\%) and development (58\% irrigated), the average productivity of rice is still low, i.e. 2.49 tonne/ha (ref. 2) because of the diversity in its growing environments, management levels and production constraints which vary spatially and temporally.

There are several factors influencing yield like genotype, environment, fertilizer and pesticide use and management practices. Conducting trials with various combinations of these factors for estimating optimum crop production is quite complex and expensive. Influence of these factors on rice productivity can be effectively estimated through different rice growth models. Crop growth models are mainly used to better understand the processes

\footnotetext{
*For correspondence. (e-mail: bandasailaja@gmail.com)
}

involved in crop production and as a tool for managing agricultural systems and support to operational and tactical decision making ${ }^{3}$. Extensive use of crop simulation models has also been suggested to increase the efficiency of different trials. Further, the models can help to compare experimental research findings across sites; extrapolate experimental field data to wider environments; develop management recommendations and decision support systems, explore effects of climatic change and make yield predictions ${ }^{4,5}$. Furthermore, the projected changes in climate and global warming conditions will further complicate the management of rice crop, as the present crop husbandry practices may need to be modified for future climatic conditions. Assessing the impact of these changes on future crop yields is complex, as yield is a result of interactions between temperature, precipitation effects and direct physiological effects of increased $\mathrm{CO}_{2}$ (ref. 6). There have been few studies about the climatecrop interaction. Osbrone ${ }^{7}$ showed that the climate-crop interaction could significantly affect a yearly variation in crop productivity. Crop simulations conducted using Oryza2000 model at six locations showed that an increase in temperature caused a decrease in yields and an increase in $\mathrm{CO}_{2}$ levels influenced an increase in yields in all locations ${ }^{8}$.

Therefore integrating climate and crop models and estimating optimum crop production with future estimated climate data as input to crop model is the only way to achieve a fully consistent view of the effects of global change on crop production. Even though these models capture temporal variations, spatial variability in soils and climate are not considered in these models. The scope of applicability of the simulation models can then be extended to a broader scale by providing spatially varying inputs (soil, weather, crop management) and analysing the outputs in a geographical information system (GIS) environment ${ }^{9}$.

Recent advances in GIS technology facilitate seamless integration of GIS and computer-based modelling. Wheat simulation model WTGROWS was developed using GIS techniques and remote sensing data ${ }^{10}$. GIS and crop growth models were combined to determine the best rice-growing environments $^{11}$. All these models require knowledge of computers and crop physiology. Different Information 
and Communication Technology (ICT) tools in agriculture have been utilized to assist farmers in decision making $^{12}$.

Decision support system (DSS) is widely applied in various parts of India for different agricultural management activities. Crop productivity being one such activity, has given considerably good results using DSS. The first simulation-based DSS comprising soil module, weather module and crop module was called as decision support system for agro-technological transfer (DSSAT) ${ }^{13}$. In DSSAT also, user has to explore input files before entering into DSS environment. With this background, a spatial decision support system has been developed for rice crop management by integrating climate, crop and GIS layers to estimate rice yield and soil-water balance at polygon or pixel level using different options of management practices and to reduce the complexity of understanding simulation models and increasing the usability of the models to reach to the common user.

\section{Methodology}

The spatial rice decision support system (SRDSS) consists of organized databases holding spatial and temporal data of local conditions, climate and crop models for simulating the growth of rice crop. Together, the data and models are linked and used as decision aids for farm level decision-making on various aspects of rice crop management. ArcGIS environment is used as an interface between data and models and to display the spatial variations in resources and impacts of decisions. A conceptual diagram of the framework is shown in Figure 1.

The methodology consists of the following steps: (a) Analysing selected climate and crop models and creating spatial and temporal datasets. (b) Developing DSS to integrate these models with GIS layers. (c) Validating DSS under local field conditions.

\section{Analysing selected climate and crop models and creating spatial and temporal datasets}

ClimGen climate model was selected to integrate with the crop model. ClimGen is a weather generator that uses principles similar to those in $\mathrm{WGEN}^{14}$. It is a daily timestep stochastic model that generates daily precipitation, minimum and maximum temperature, solar radiation, humidity and wind speed data series with statistics similar to that of the historical weather data. The model requires inputs of daily series of these weather variables to calculate parameters used in the generation process for any length of period at a location of interest. It performs well in the simulation of weather data series. This has relevance for agricultural modelling applications where there is a limited observed record ${ }^{15}$. This model was validated using daily weather data from 1984 to 2009 of
Indian Institute of Rice Research (earlier DRR) farm (17.32 N, 78.38 E) and estimated values for 2010-2050 and data of 2011-2013 were used as observed data. ClimGen model showed good performance in comparing the observed values for weather parameters like temperature, wind speed and relative humidity. However, its performance was not effective in estimating rainfall. Rainfall estimation module was separately developed using historical data and learning algorithms ${ }^{16}$.

Oryza2000 model was chosen as crop model for this study. Oryza2000 (ref. 17) model is an eco-physiological crop model to simulate growth and development of a rice crop in situations of potential production, water limitations and nitrogen limitations.

The model was validated under limited nitrogen and water situations and data used were kept free from weeds, pests and diseases as possible. The data sets to validate the crop model were derived from field experiments conducted at the research farm of Directorate of Rice Research at Rajendranagar, Hyderabad, India. Performance of this validation was successfully evaluated using D-Index and N-statistical tests ${ }^{3}$. The input and output parameters of ClimGen and Oryza2000 models were analysed for developing DSS interface.

The input files required for ClimGen model are historical weather data file (minimum 10 years data) and location file. The basic input requirements of the model are daily weather, experimental, crop and soil data sets. Development growth parameters for four stages of rice crop is calculated based on the sowing dates of crop and day-wise weather data. These parameters are used in the crop file for estimating growth of rice crop. minimum dataset required to execute Oryza2000 model is shown in Table 1.

One of the major rice growing districts, Nalgonda of Telangana state was selected for developing different modules of DSS. Major data sets required in the development of DSS are the data sets required for the above models.

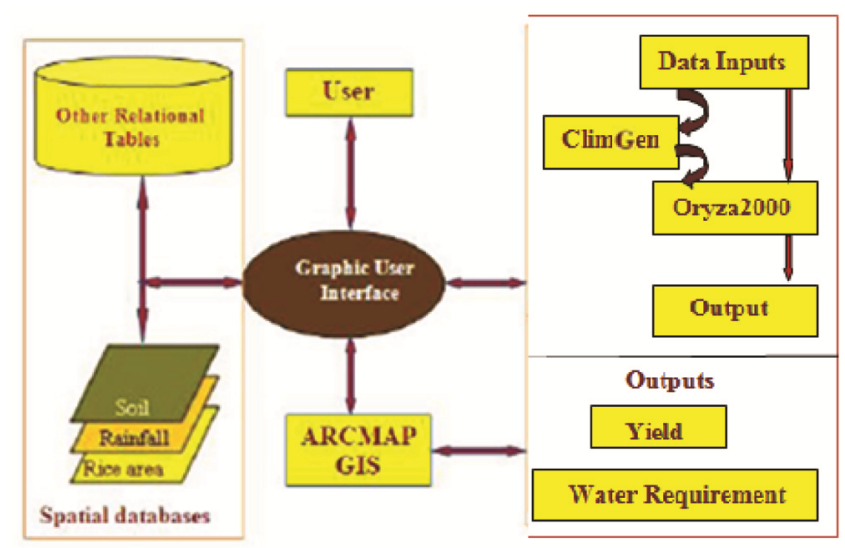

Figure 1. Structure of interface for spatial rice decision support system (SRDSS). 
Table 1. Input files and parameters for ClimGen and Oryza2000 models

\begin{tabular}{ll}
\hline Model & \multicolumn{1}{c}{ Input files and parameters } \\
\hline ClimGen & $\begin{array}{l}\text { Location file: Longitude, latitude and elevation } \\
\text { Weather file: Day wise precipitation, maximum and minimum temperatures, relative humidity, } \\
\text { wind speed and solar radiation. }\end{array}$ \\
Oryza2000 & $\begin{array}{l}\text { Weather file: Longitude, latitude, elevation and Angstrom parameters, day-wise sunshine hours, } \\
\text { maximum and minimum temperatures, vapour pressure, wind speed and precipitation. }\end{array}$ \\
& $\begin{array}{l}\text { Experimental file: Location and name of weather file, production situation (potential production, } \\
\text { limited nitrogen, limited water, limited nitrogen and water situations) crop growing dates, } \\
\text { nitrogen and irrigation applied and dates of application. } \\
\text { Crop file: Crop growing parameters. } \\
\text { Soil file: Depth of soil, available water capacity, field capacity and permanent wilting point. }\end{array}$ \\
&
\end{tabular}

Soilwater.mdb

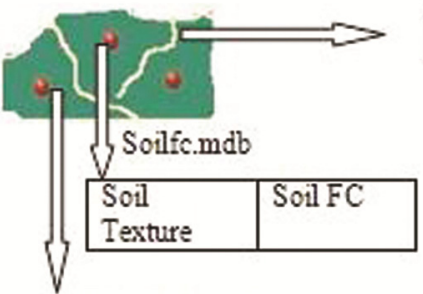

FinalSoil.mdb

\begin{tabular}{|l|l|l|l|l|l|}
\hline Soil Group & Texture & depth & awc & fc & watbal \\
\hline
\end{tabular}

Figure 2. Relational tables of soil (fc, field capacity; awc, available water capacity and watbal, water balance).

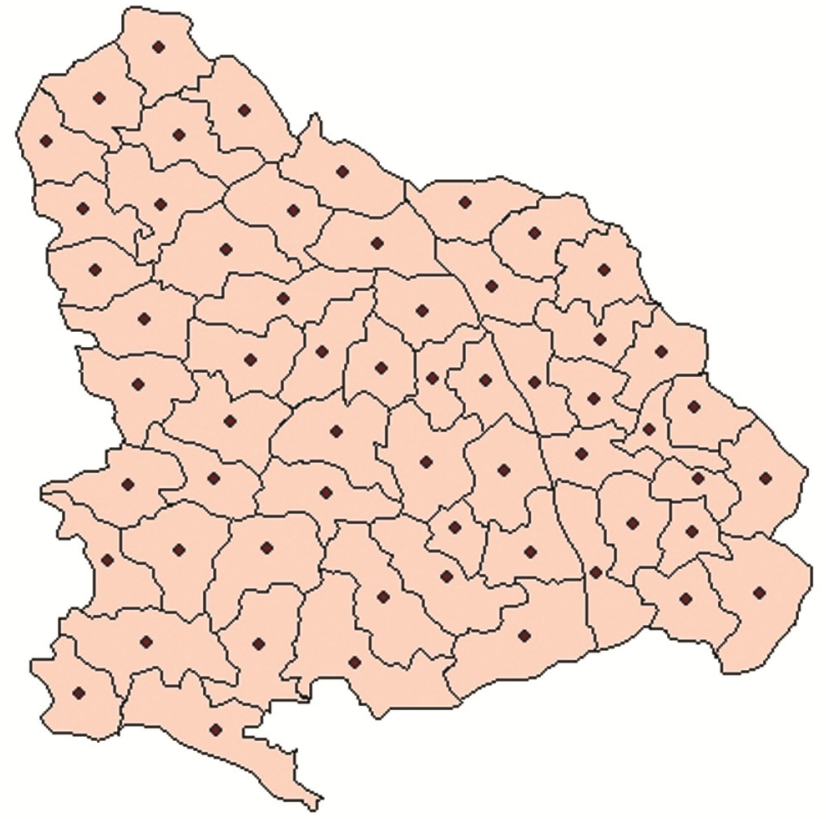

Figure 3. Rain gauge stations of Nalgonda district.

\section{Spatial data}

The spatial data used for developing DSS for rice management at district level are weather, soil and classified rice area map of Nalgonda district. GIS is the main environment for creating spatial databases. GIS is used as the front-end tool for data pre-processing and as the visualization tool for analysing the final results ${ }^{18}$. It helps to link data from different sources together and is an important tool for finding data spatially ${ }^{19}$. ArcGIS 9.0 package was used creating these spatial databases. Mandal map of Nalgonda was digitized using adequate number of welldistributed ground control points (GCPs).

\section{Soil layer}

Soil map of Nalgonda was extracted from a soil map of Andhra Pradesh using the boundary of Nalgonda. A spatial database was designed to store and manage soil data at the series level. The spatial data were stored as ArcGIS coverages and other soil tables were created in MS Access. Among soil attributes, soil texture, field capacity (fc), available water capacity (awc) and soil depth are important attributes for estimating water balance for rice crop. All five variables except field capacities were available with the attribute table of soil map. Soils of Nalgonda were grouped by soil texture, depth and awc attributes of Nalgonda soil map. Murthy et $a .^{20}$ listed field capacity (FC) and permanent witting point (PWP) values for different soil textural layers of a limited number of benchmark soil profiles in India. A difficulty with soil textural grouping is that soil texture varies with depth. Data regarding water storage limitations of soil profiles, FC and PWP values are essential for running soil-water balance models ${ }^{21}$. Soil texture-wise field capacities were referred from this reference and entered into soil table. A structure of soil database is shown in Figure 2.

\section{Rainfall data}

Daily rainfall is required as a climatic data input for Oryza2000 model. In this study, 59 mandals were considered as 59 rainfall stations and point features were created in ArcGIS (Figure 3). Thiessen method of spatial 
interpolation was used to generate the influence of rainfall polygons in ArcGIS environment (Figure 4). A similar Thiessen method was used for creating rainfall zones in RDSS project in Thailand ${ }^{22}$. Nalgonda boundary map was used to clip Thiessen polygons within the boundary. Each mandal contained more than 2 Thiessen polygons and soil groups.

\section{Overlay of soil and weather data}

Soil map and Thiessen polygon map of Nalgonda district were overlaid. This map was used further with SRDSS for polygon-wise yield estimation.

\section{Temporal data}

Mandal-wise weather data (daily) of Nalgonda was collected from Department of Economics and Statistics, Hyderabad. Rice yield data for the year 2004-05 was collected from Joint Director of Agriculture, Nalgonda. A block level database was designed using MS Access.

\section{Developing DSS to integrate these models with GIS layers}

The databases (spatial and temporal) and models were integrated into a DSS using Map Objects 2.0 with Visual Basic in Microsoft Access. Graphic user interface (GUI) of DSS was designed to link spatial databases with ClimGen and Oryza2000 rice model in order to facilitate the selection of target area, management parameters and different scenarios for rice yield prediction and mapping.

The integration was customized for easy interactive use and working at the user level. Microsoft Access was used as back end for designing relational tables for soil, weather and location. Shoreline Management System was developed using Map Objects and MS Access ${ }^{18}$. The following 3 interfaces were designed for SRDSS. (i) Climate interface for entering climate data/ClimGen generated climate data. (ii) Oryza2000 model interface for entering model parameters. (iii) Spatial interface for entering soil and weather layers.

In the climate interface, ClimGen model was used only for estimating yield for future weather conditions. A program was written to convert output file of ClimGen into the input file of Oryza2000 model. These interfaces were designed using simple text boxes, command buttons for easy understanding by common user. Rice yield was estimated using the 'Run Oryza' command button. The formula used for soil-water balance in Oryza2000 model $^{14}$ is

Water balance $(\mathrm{dw})=I+R+C-E-T-S-P-D$, where (all units in $\mathrm{mm} \mathrm{day}^{-1}$ ) $\mathrm{dw}$ is the change in stored water, $I$ the irrigation supply, $R$ the rainfall, $C$ the capillary rise, $E$ the evaporation, $T$ the transpiration, $S$ the seepage, $P$ the percolation and $D$ is the surface drainage/runoff (bund overflow).

\section{Validating DSS under local field conditions}

Different data sets were used for validating individual components of DSS for rice production management. Two approaches were used to validate DSS. One approach was to compare the DSS derived yield at mandal level with reported data for the year 2004. The second approach was to compare DSS yield and yield estimated by remote sensing method ${ }^{23}$.

SRDSS was validated with the data of Miryalaguda mandal of Nalgonda for 2004-05. In the first approach, the model was run for mid-duration varieties under limited nitrogen and water situations. Mandal rice yield and soil-water balance were estimated. Input parameters were dates of sowing, transplanting, panicle initiation, flowering and maturity, weather and management data for limited nitrogen and water situations (Table 2). Weather data of 2004 was entered through DSS climate interface. In this case, the model required additional data regarding nitrogen $(\mathrm{N})$ and water limitations. This included amount of $\mathrm{N}$ applied and corresponding date, amount of irrigation water applied $(20 \mathrm{~mm})$ and number of days after disappearance of ponded water (one day). The $\mathrm{N}$ dose of 120 to $190 \mathrm{~kg} / \mathrm{ha}$ is being followed by majority of rice farmers in Nalgonda ${ }^{24}$. The average amount of $\mathrm{N}$ to be applied for the model was chosen as $150 \mathrm{~kg} / \mathrm{ha}$. Soil field capacities, available water capacity and depth data were taken from soil layer. These attributes were input to paddy data file used exclusively for limiting water condition. Dates of

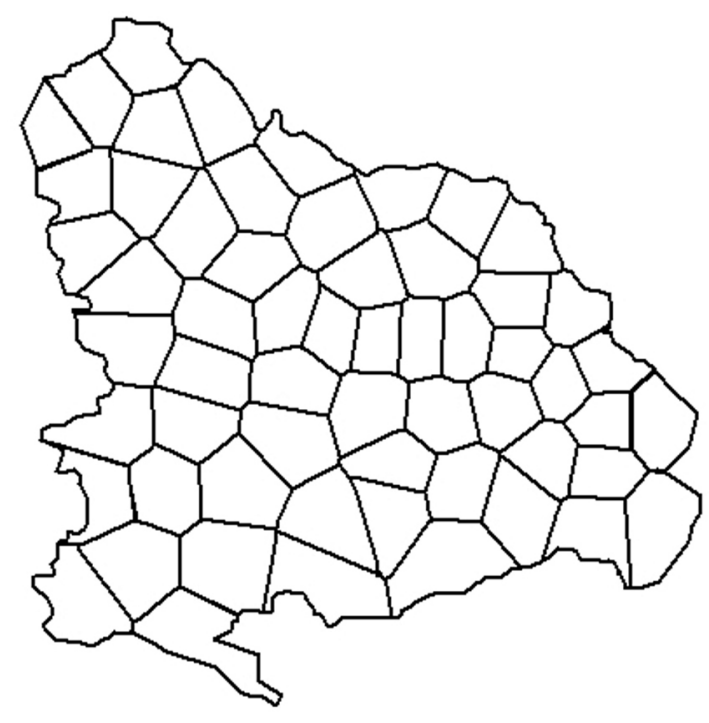

Figure 4. Thiessen polygons of 59 rain gauge stations. 
Table 2. Input parameters used for SRDSS under nitrogen and water limited situation for Miryalaguda mandal

\begin{tabular}{|c|c|}
\hline Parameters & Input data \\
\hline Production situation & Limited nitrogen and water \\
\hline \multirow[t]{5}{*}{ Crop growing dates } & Sowing date: 15 July 2004 \\
\hline & Transplanting date: 10 August 2004 \\
\hline & Panicle initiation date: 12 September 2004 \\
\hline & Flowering date: 16 October 2004 \\
\hline & Maturity date: 20 November 2014 \\
\hline Variety & Medium duration (125 days) \\
\hline \multirow[t]{4}{*}{ Nitrogen application parameters } & Amount applied (kg/ha) \\
\hline & 15 September 2004 \\
\hline & 1 October 2004 \\
\hline & 17 November 2004 \\
\hline \multirow[t]{2}{*}{ Irrigation applied } & Amount: $20 \mathrm{~mm}$ \\
\hline & Alternate days \\
\hline Weather data & Day-wise weather data starting from 15 July 2004 to 20 November 2014 \\
\hline
\end{tabular}
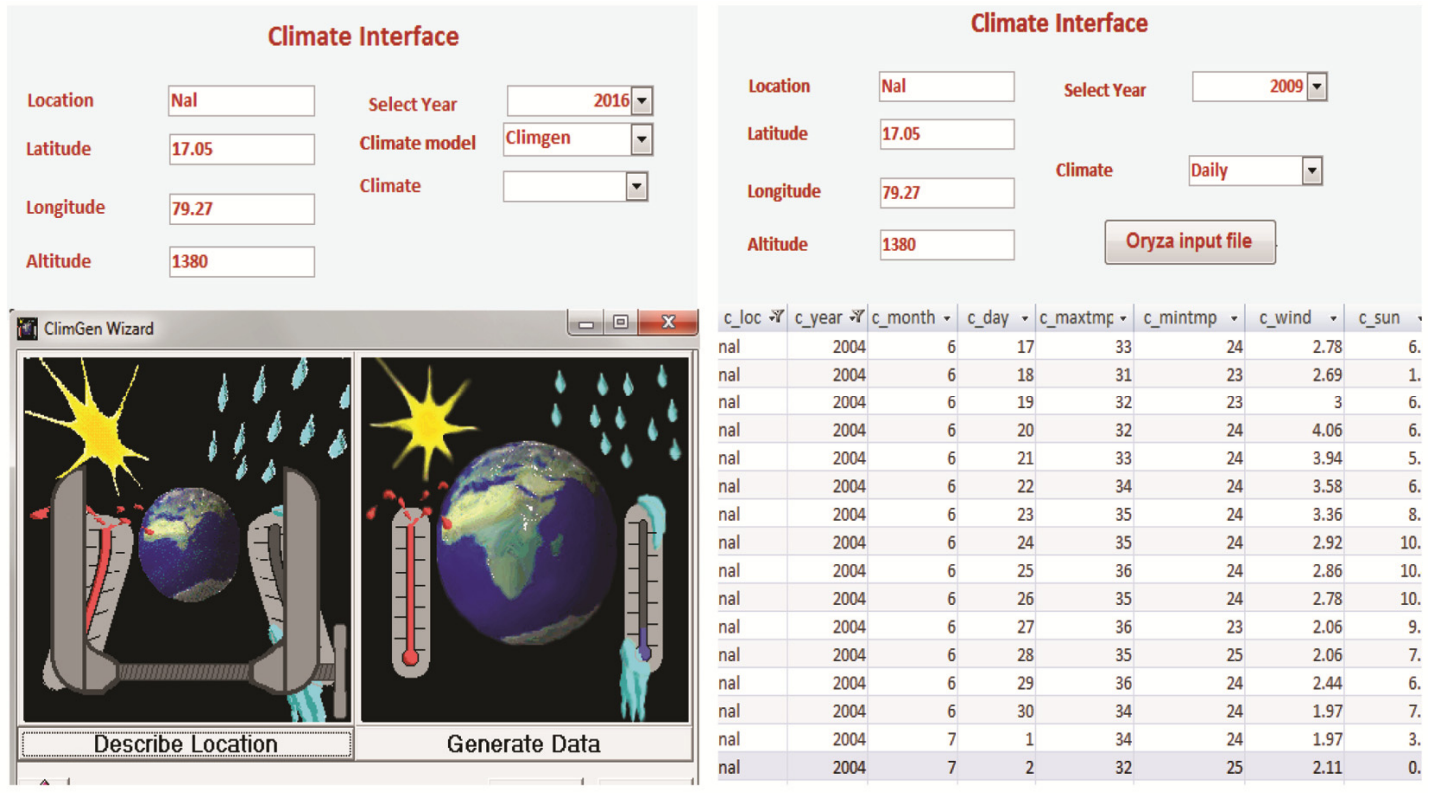

Figure 5. Climate interface of SRDSS.

crop growing period and other management parameters were entered through model interface of DSS and the model was run for these input files. Miryalaguda mandal layer was extracted from an overlaid map of soil and weather layers of Nalgonda and these layers were added through spatial interface and using Thiessen-wise rice yield and soil-water balance buttons, polygon-wise yield and soil-water balance were estimated. In the second approach, soil map was overlaid on pixel-wise yield map estimated from IRS 1D LISS III satellite image. Pixelwise yield values were averaged for each soil group using the attribute table of overlaid map of soil and pixel-wise rice yield maps. These estimated values from SRDSS were compared with reported values and yield estimated from remote sensing.

\section{Results}

Results on the development of each component of DSS and validation of DSS at mandal level are presented below.

\section{Development of DSS}

The DSS GUI was designed to link spatial databases with ClimGen and Oryza2000 models in order to facilitate the selection of target area, management strategies and various scenarios for rice yield prediction and mapping. Customized screens were created for entering the input data for the model. There are three main interlinked 


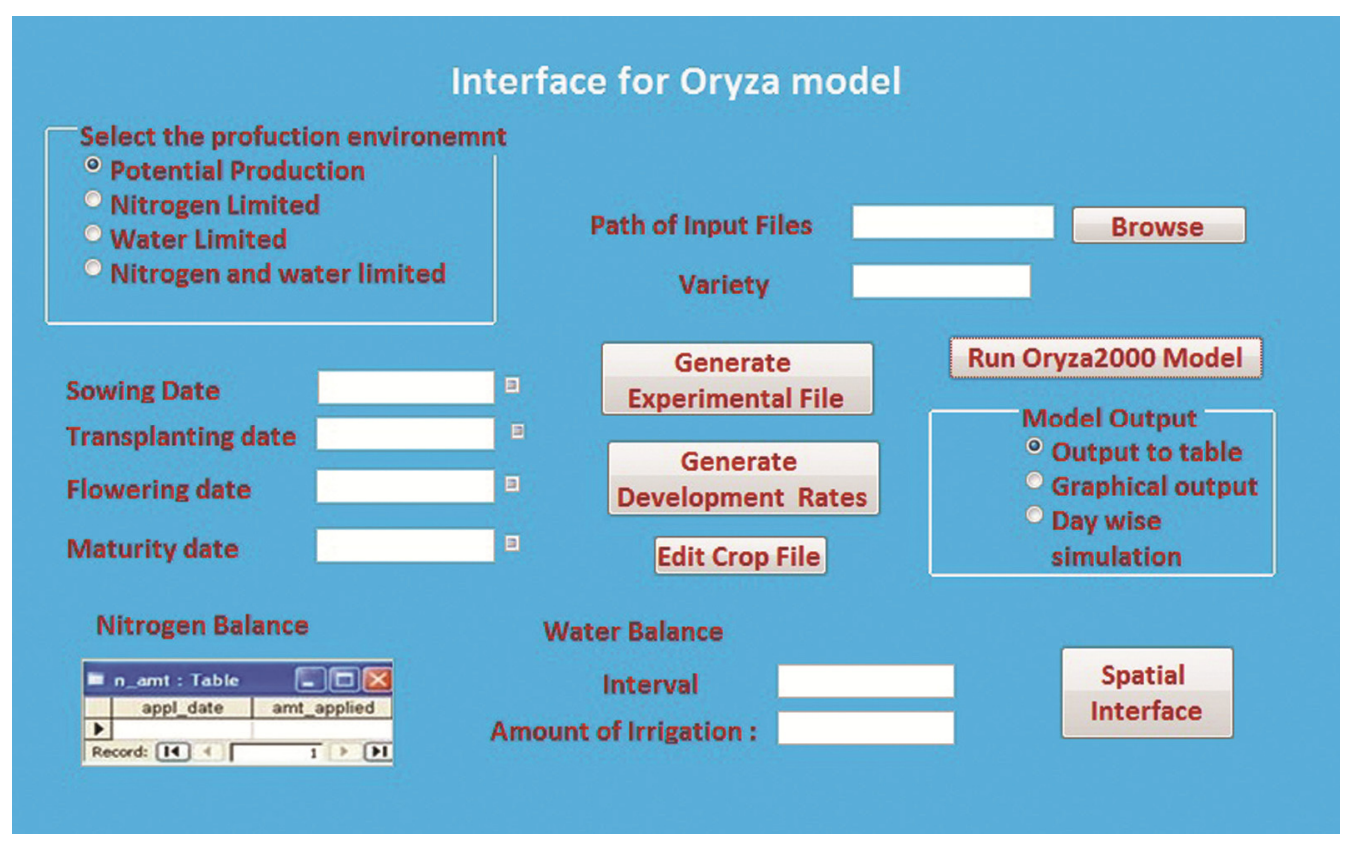

Figure 6. Crop model interface of SRDSS.

interfaces, namely climate, Oryza2000 model and spatial interface. In 2008, Saad et al. ${ }^{25}$ developed IDSS Prototype-IndiCA consisting of the following subsystems - IndiCA1, IndiCA2 and Pest Management as interfaces.

In the DSS interface, first, the user has to enter location details and select the year from drop down box. If the year is less than/equal to current year, then the system prompts for weather data otherwise ClimGen model generated data interface will be displayed (Figure 5). The second interface prompts for Oryza2000 model parameters. There are four production situations in Oryza2000 model. Based on the production situations option, situation-specific input parameters appear on the screen (Figure 6). Common parameters for three situations (potential, nitrogen limited and water limited) are displayed constantly.

The interface then prompts for model parameters path of the input files, dates of crop growing, variety name, etc. and using the button 'Generate Data File' experimental data file will be generated (Figure 6). This is followed by variety specific development rates button 'Generate Development Rates' and these rates will be placed in crop file using the button 'Edit Crop File' and finally model will be run by 'Run Oryza2000 model' command button. The output files generated by this model will be displayed by choosing the options from 'Model Output Box' and the spatial interface is invoked by clicking on the button 'Spatial interface'.

Third interface is the spatial interface (Figure 7). The main subscreens in spatial interface are rain gauge stations-wise area, production and yield estimation, and soil-water balance. As seen in Figure 7, all these attributes of GIS layers can be accessed by adding layer using 'Add layers' to the map window of the interface. Different combo boxes help the user to select certain attributes (fields) of the layer chosen and select number of classes for displaying the attribute in a range of colours, i.e. starting and ending colour ramps to display the image. User can select as many combinations as needed. There are four command buttons in rain gauge stations subscreen. Thiessen polygon-wise rice yield is computed using the 'Thiessen wise yield' button. If rice area classified map (satellite image) is available, then area shape file can be added to the map layer, and using 'Rice_area' button polygon-wise rice area will be calculated and updated to the Thiessen layer. Otherwise, by using 'Enter rice area' button, user can enter the rain gauge-wise rice area data. Then by clicking on the button 'Rice production', rice production will be calculated and updated to the Thiessen layer.

The command buttons used for estimating soil-water balance are shown in Figure 7. First, user has to add soil layer by selecting soil layers from the 'Add layers' drop down box. Using 'Soil attributes' button, soil texture, depth and awc fields from the soil layer will be selected and copied into temporary table 'soil water'. Then by using 'edit field capacities', texture-wise field capacities can be edited. 'update final soil' button creates intermediate tables 'soil groups' and 'final soil'. 'soil groups' table contains specific records for combination of fields such as soil texture, depth and awc of Nalgonda soil map and generates unique Ids to each group. By pressing 'soil water balance' button, soil-water balance will be estimated and using 'update soil layer' soil-water balance fields of soil layer will be updated. All these attributes of 


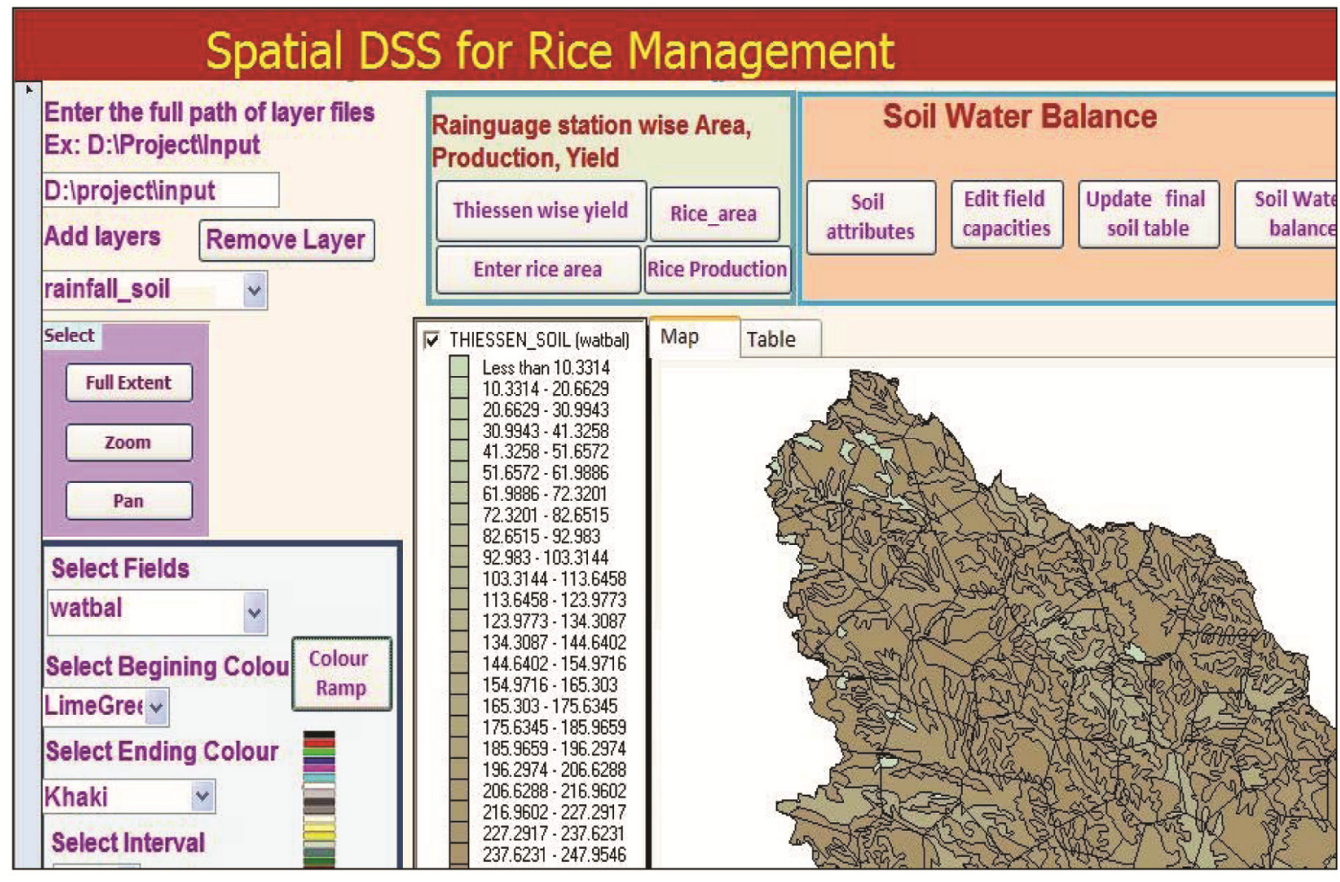

Figure 7. Spatial interface of SRDSS.

Table 3. Attributes of soil map of Miryalaguda mandal used for SRDSS

\begin{tabular}{rlcrc}
\hline Soil group & \multicolumn{1}{c}{ Soil type } & Soil depth $(\mathrm{mm})$ & Soil awc $(\%)$ & Soil FC (\%) \\
\hline 7 & Clayey, calcareous & 24 & 9 & 37 \\
11 & Cracking clay, calcareous & 16 & 15 & 30 \\
18 & Gravelly clay & 13 & 6 & 17 \\
23 & Gravelly loam & 8 & 1 & 14 \\
25 & Gravelly loam & 13 & 6 & 14 \\
\hline
\end{tabular}

Table 4. Rice yield estimated for Miryalaguda mandal under limited nitrogen and water situation with $150 \mathrm{~N}$ and $20 \mathrm{~mm}$ irrigation with one day interval

\begin{tabular}{rccc}
\hline Soil group & Thiessen Id & $\begin{array}{c}\text { Rice yield } \\
\text { (tonne/ha) }\end{array}$ & $\begin{array}{c}\text { Water balance } \\
(\mathrm{mm})\end{array}$ \\
\hline 11 & 34 & 4.058 & 105.00 \\
18 & 41 & 4.542 & 190.00 \\
23 & 34 & 4.200 & 224.40 \\
18 & 44 & 4.655 & 196.11 \\
7 & 44 & 4.555 & 185.91 \\
23 & 44 & 4.239 & 196.11 \\
25 & 44 & 4.654 & 196.11 \\
11 & 44 & 4.502 & 224.40 \\
18 & 50 & 4.530 & 185.34 \\
23 & 51 & 3.206 & 216.00 \\
7 & 51 & 4.317 & 172.00 \\
11 & 51 & 4.235 & 190.37 \\
& Average & 4.36 & 190.14 \\
\hline
\end{tabular}

soil water can be accessed by adding soil layer and selecting different display options discussed above.

After calculating rice yield and soil-water balance, these two layers will be overlaid on rice area layer (if available) and mandal-wise soil-water balance, rice yield and production can be estimated.

\section{Validating DSS under local field conditions}

Soil groups were created for Nalgonda by considering unique values of soil texture, available water capacities and depth. Nalgonda soils were divided into 31 soil groups. Miryalaguda mandal soil and Thiessen maps were extracted. There were totally five soil groups (Table 3) in Miryalaguda mandal and five Thiessen polygons. The overlay map of Thiessen and soils of Miryalaguda contained 12 combinations of soil and Thiessen polygons (Figure 8).

In this study, crop yield for Miryalaguda mandal was estimated using two methods: (i) GIS based DSS, i.e. SRDSS derived yield and (ii) Satellite image derived yield.

In the first method, rice yield was estimated from soil and theissen overlaid map (Table 4). The estimated yield varied from 4.05 tonne/ha to 4.65 tonne/ha. The average yield was close to the yield estimates from crop cutting 
experiments (5.05 tonne/ha) conducted by Department of Agriculture in the Kharif season during 2004. There was slight variation among polygon-wise rice yields estimated by SRDSS (Figure 8 ).

In the second method, rice yield was estimated by overlay of satellite image derived yield map with soil group map of Miryalaguda mandal. Rice yield estimated from LISS III satellite image for Miryalaguda mandal was approximately 5 tonne/ha (ref. 23). Each soil groupwise rice yield pixels were averaged (Figure 9). The yield estimated from GIS and models was 4.36 tonne/ha, almost close to satellite image derived yield. Soil groupwise yields for Miryalaguda mandal estimated from remote sensing and by SRDSS are given in Table 5 . There is a $15 \%$ variation in the average yields at mandal level between these two approaches. Remote sensing yields were higher compared to the yields estimated from SRDSS, but both followed similar trends with soil group variations. In one soil group (25), the value was quite close (4.65 tonne/ha) to the satellite-derived rice yield (5 tonne/ha) for Miryalaguda mandal.

Soil and Thiessen group-wise water balance was estimated (Table 4). Cumulative irrigation and rainfall, evaporation and transpiration were output values of

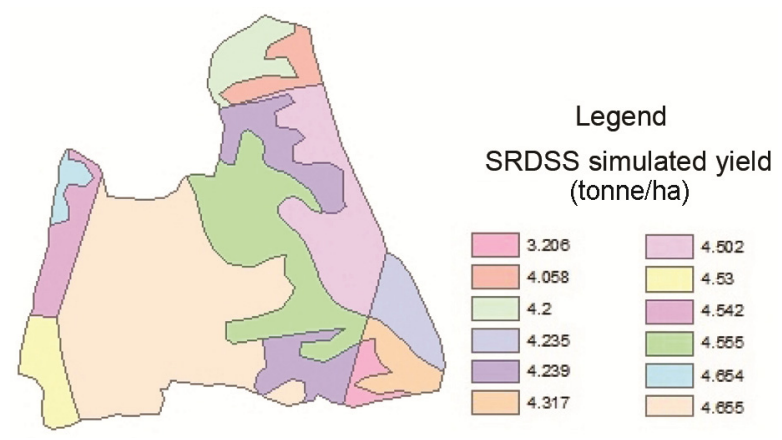

Figure 8. Rice yield estimated from the overlay of soil and Thiessen layers of SRDSS.

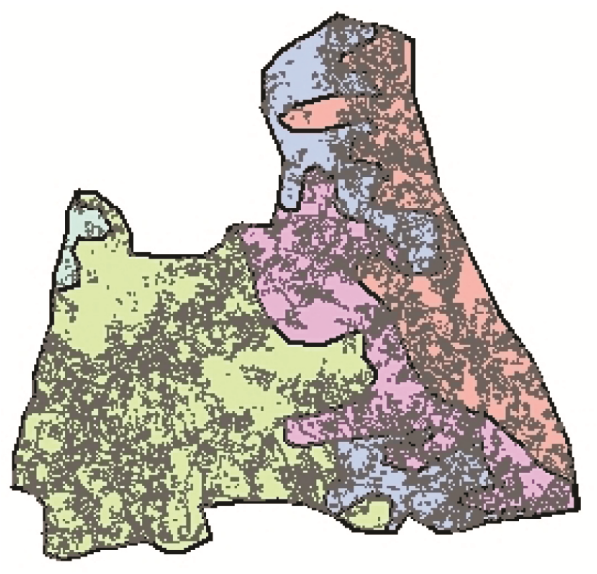

Legend

Soil group

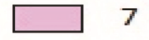

$\square: 11$
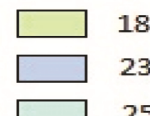

Figure 9. Overlay of soil and pixel-wise rice yield maps of Miryalaguda mandal.
Oryza2000 model under limited water condition. Wilting point was calculated by computing the difference between field capacity and available water capacity. Using eq. (1) soil-water balance was computed. Estimated soil-water balance varied among soil and Thiessen groups from 105 to $224 \mathrm{~mm}$.

\section{Discussion}

SRDSS provides consistent decision support in predicting rice yields for existing and future climate. Unlike other crop models that are data intensive with many input files, this DSS requires minimal data like crop growing dates, day-wise weather, amount of application of nitrogen and irrigation and corresponding dates of application. While SRDSS results depend on specific location, they are also sensitive to soil and climate parameters.

SRDSS interface was designed using Visual Basic and Map Objects with Microsoft Access as back end. These interfaces are simple and menu driven. Satti et al. ${ }^{18}$ developed an user interface for GIS-based Water Resources and Agricultural Permitting and Planning System (GWRAPPS), using Visual Basic, resides within GIS and facilitates location-specific and crop-specific data input. Soil and rainfall (Theissen) maps were generated using ArcGIS package. There are several open source packages available for GIS and rainfall and soil maps in IMD Portal and Krishi Geo-Portal ${ }^{26}$. Since these maps are readily available, users can add these maps to map window and estimate yield and water balance. The Changwat DSS shell 1.0 interface allows users to link the DSSAT4 simulation models with spatial databases under Windows PC environment ${ }^{27}$. Users can easily adopt SRDSS even without in-depth knowledge on crop models and GIS. Using the climate and Oryza2000 model interfaces, user can estimate yield for different management practices like shifting of sowing date, application of fertilizer or irrigation, etc. and select optimum management to obtain the targeted yield for the selected location.

Another important output is soil-water balance. Soilwater balance is estimated by selecting soil layer, weather

Table 5. Comparison of remote sensing and SRDSS yields of Miryalaguda mandal during 2004-05, kharif season

\begin{tabular}{lccc}
\hline Soil group & $\begin{array}{c}\text { Estimated yield } \\
\text { from remote } \\
\text { sensing (t/ha) }\end{array}$ & $\begin{array}{c}\text { Estimated yield } \\
\text { from } \\
\text { SRDSS (t/ha) }\end{array}$ & $\begin{array}{c}\text { Percentage } \\
\text { difference (\%) }\end{array}$ \\
\hline 7 & 5.47 & 4.44 & 23.31 \\
11 & 5.73 & 4.27 & 34.30 \\
18 & 4.73 & 4.536 & 3.43 \\
23 & 4.55 & 3.89 & 16.87 \\
25 & 4.67 & 4.65 & 0.28 \\
Average & 5.03 & 4.36 & 15.23 \\
\hline
\end{tabular}


data and crop growing dates. Soil texture plays an important role in estimating water balance of the selected area. The model runs soil polygon-wise and generates outputs. The output file contains weight of rough rice (WRR14), cumulative rainfall in main field (RAINC, mm), cumulative irrigation in main field (IRC, $\mathrm{mm}$ ), cumulative actual transpiration from crop in main field (TRWC, $\mathrm{mm}$ ) and cumulative actual evaporation from soil in main field (EVSWC, mm). Water balance is calculated by eq. (1). Amount of irrigation and day interval between irrigation are the inputs to the model. User can change these parameters and check water balance to maximize the rice yield. In reverse user can also estimate irrigation requirement for the crop growing period.

A traditional Oryza2000 model and DSS can be compared mainly in terms of input parameters. Understanding input and output files of Oryza2000 model will be difficult for an user without computer/crop physiology knowledge. On the other hand, users without expertise in computers/crop models can easily use DSS. As soil, water and climate are spatial variables, the performance of Oryza2000 model can be increased by linking it to GIS environment. Applicability of these models can be extended to much broader spatial scales by combining them with a GIS ${ }^{28}$. Such an integrated model will assist in the presentation and understanding of soil/water and crop growth variables on a spatial scale ${ }^{29}$.

Mandal-wise rainfall and soil layers of Miryalaguda mandal, Nalgonda and rice area classified using remote sensing were used as input layers to SRDSS. Weather and soil data were major inputs to this model. SRDSS predicted average yield estimated for different soil groups and Thiessen polygon was approximately 4.36 tonne/ha for the study area. Yield estimated by SRDSS was $15 \%$ lower than the yield estimated from crop cutting experiments of Department of Agriculture (5.05 tonne/ha). As reported in production-oriented survey of Directorate of Rice Research (DRR) (2004), the yields in non command area of Miryalaguda mandal ranged from 6 to 7 tonne/ha and in command areas ranged from 5 to 6 tonne/ha. SRDSS yield is close to the yield reported (command areas) by this survey. Mandal-wise weather data on radiation and temperatures were not available, so district level data was used. Mandal-wise rainfall data was only available. SRDSS was validated with mandal (rain gauge station) wise weather data (variation only in rainfall). Difference in simulated yield values is due to rainfall, coordinates (longitude and latitude) and soil attributes. If all weather parameters are available mandal (rain gauge station) wise, simulation results might improve further.

The yield estimated from satellite image ( 5 tonne/ha) is more close to the observed values (5.05 tonne/ha). If pixel-wise weather data is available, then yield can be estimated at pixel level also through SRDSS. Hence, simulation of SRDSS is fully dependent on the precision of input values.

\section{Summary and conclusion}

Rice is the world's most important food crop and a primary source of food for more than half of the world's population. As population continues to grow and to achieve the targeted yield of 120-130 million tonnes by 2025 , increasing rice productivity is crucial. Influence of soil, water and climatic variables on rice productivity can be effectively estimated through different rice models. Integrating ClimGen model with Oryza2000 improves the efficiency of DSS to simulate the impact of future climatic conditions on rice yield and devise appropriate location-specific management practices in light of changing climate. Since soil, water and climate are based on spatial dimensions, Oryza model is integrated with GIS to increase its performance. As different components are involved in management of rice crop like crop modelling, physiology (weather and crop growth), agronomy (management practices) and spatial technologies, i.e. remote sensing and GIS, a common user or a planner or researcher may not have knowledge in all these components. Hence for effective rice management, a common interface was designed to access all these components for proper decision making. This DSS was validated with Miryalaguda mandal data and the results were verified with observed values. SRDSS was found to be encouraging as it provided an opportunity for planners, researchers, economists and common users to analyse situations and discuss simulation results and identify potential research directions. Further, SRDSS can be integrated with sensors, economic, marketing models and mobile applications to support farmers at each stage of crop management. Adoption of SRDSS will facilitate simulation of yields on regional or national scale which will help researchers and decision-makers to understand the status and extent of climate, soils, crop cum field management effects on rice crop as well as other crops.

1. http://wgdpkerala.org/images/pdf/Soil_Information_System.pdf (accessed on 29 August 2018).

2. http://www.indiaagristat.co.in, Area, Production, Productivity of Rice Crop (accessed on 29 August 2018).

3. Sailaja, B., Voleti, S. R., Subrahmanyam, D., Rao, N. H. and Nathawat, M. S., Validation of Oryza2000 model under combined nitrogen and water limited situations. Indian J. Plant Physiol., 2013, 18(1), 31-40.

4. Bouman, B. A. M., Van Keulen, H., Van Laar, H. H. and Rabbinge, R., The school of de Wit' crop growth simulation models: pedigree and historical overview. Agric. Syst., 1996, 52, 171-198.

5. Jones, J. W. et al., The DSSAT cropping system model. Eur J. Agron., 2003, 18, 235-265.

6. Parry, M., Rosenzweig, C., Iglesias, A., Livermore, M. and Fischer, G., Effects of climate change on global food production under Sres emissions and socio-economic scenarios. Global Environ. Change, 2004, 14(1), 53-67.

7. Osborne, T., Slingo, J. M., Lawrence, D. M. and Wheeler, T. R., Examining the interaction of growing crops with local climate using a coupled crop-climate model. J. Clim., 2009, 22, 1393-1411. 
8. Sailaja, B., Voleti, S. R., Gayatri, S., Subrahmanyam, D., Nagarjuna Kumar, R., Rao, R. and Meera, S. N., Vulnerability of rice yields under changed climatic conditions. Int. J. Agric. Stat. Sci., 2015, 11(2), 523-526.

9. Dadhwal, V. K., Sehgal, V. K., Singh, R. P. and Rajak, D. R., Wheat yield modeling using satellite remote sensing with weather data. Recent Indian experience. Mausam, 2003, 54(1), 253-262.

10. Sehgal, V. K., Rajpurohit, H. S., Mariappan, V. E. N., Rajak, D. R., Rao, A. and Dadhwal, V. K., Spatial implementation of WT grows crop simulation model for regional wheat yield mapping, 2008; http://www.gisdevelopment.net/application/agriculture/yield/ agric0009.htm

11. Shu Fukai, Increased productivity of rice-based cropping systems in Lao PDR, Cambodia and Australia, 2005; http://aciar. gov.au/project/cim/1999/048

12. Taechatanasat, P. and Armstrong, L., Decision support System data for farmer decision making. Proceedings of Asian Federation for Information Technology in Agriculture (ed. Perth, W. A.), Australian Society of Information and Communication Technologies in Agriculture, 2014, pp. 472-486; http://ro.ecu.edu.au/ecuworkspost $2013 / 855$

13. Vidya, K. and Singh, T. P., A comprehensive study of application of decision support system in agriculture in Indian context. Int. J. Comput. Appl., 2013, 63(14), 6-11.

14. Richardson, C. W. and Wright, D. A., WGEN: a model for generating weather variables. US Department of Agriculture, Agricultural Research Service, 1984; http://www.goldsim.com/Downloads/ Library/ModelLibrary/Applications/Hydrology/WGEN.pdf

15. Tingem, M., Rivington, M., Azam-Ali, S. N. and Colls, J. J., Assessment of the ClimGen stochastic weather generator at Cameroon sites. Afr. J. Environ. Sci. Technol., 2007, 1(4), 86-92.

16. Gayatri, S., Sailaja, B., Voleti, S. R. and Subrahmanyam, D., Validation of Climgen model with regional climate data. Poster presented in the 3rd International Conference on Agriculture and Horticulture, 27-29 October 2014, Hyderabad, p. 248.

17. Bouman, B. A. M., Kropff, M. J., Tuong, T. P., Wopereis, M. C. S., ten Berge, H. F. M. and van Laar, H. H., Oryza 2000: Modeling Lowland Rice, International Rice Research Institute, The Netherlands, 2000, p. 235.

18. Sudheer, S. R. and Jacobs, J. M, GIS-based model to estimate the regionally distributed drought water demand. Agric. Water Manage., 2004, 66(1), 1-13.
19. Dopsovic, R. and Franks, M., GIS Approach to Shoreline Management using MapObjects and MS Access. Paper presented at the 24th Annual ESRI International User Conference, 9-13 August 2004; http://gis.esri.com/library/userconf/proc04/docs/pap1685.pdf

20. Murthy, R. S., Hireherur, L. R., Deshpande, S. B. and Rao, B. V. V., Benchmark soils of India-morphology, characteristics and classification resources management. National Bureau of Soils and Land Use planning, Nagpur, India, 1982, 374, p. 14.

21. Rao, N. H., Grouping water storage properties of Indian soils for soil water balance model applications. Agric. Water Manage, 1998, 36, 99-109.

22. Ekasingh, M. and Kaewtip, J., Spatial interpolation of rainfall data for DSS, 2008; http://www.mcc.cmu.ac.th/research/DSSARM/ ThaiRice/soildb.html

23. Sailaja, B., Voleti, S. R., Subrahmanyam, D., Nathawat, M. S. and Rao, N. H., Regional rice yield estimation by integration of spatial technologies and crop model. J. Remote Sensing GIS, 2013, 4(2), 56-66.

24. POS-Production Oriented Survey, Directorate of Rice Research, Rajendranagar, Hyderabad, 2004.

25. Saad, P., Bakri, A., Kamaruddin, S. S. and Jaafar, M. N., INdica Intelligent decision support system for rice yield prediction in precision farming. Project Report. Faculty of Computer Science and Information System, University Technology Malasia Institutional Repository, Skudai, Johor, 2008; http://eprints.utm.my/4385/

26. Krishi Geo-Portal; https://krishi.icar.gov.in/Geo_Portal.jsp (accessed on 29 August 2018).

27. Jintrawet, A. and Sringam, P., Crop production estimation using crop models and GIS interface: a case of rice production systems, 2007; http://www.mcc.cmu.ac.th/ASIMMOD2007/downloadpdf. asp?filedownload $=\mathrm{C} 05$ Attachai\%20Jintrawet.pdf

28. Satya Priya and Shibasaki, R., National spatial crop yield simulation using GIS-based crop production model. Ecol. Model., 2001, 136(2-3), 113-129.

29. Xevi, E. and Khan, S., Integrating GIS and modelling soil water and crop production, 2006; http://www.mssanz.org.au/modsim07/ papers/21_s46/Integrating_s46_Xevi_.pdf

Received 24 June 2017; revised accepted 25 October 2018

doi: $10.18520 / \mathrm{cs} / \mathrm{v} 116 / \mathrm{i3} / 412-421$ 